\title{
Analysis of Grade Difference of TPACK Among Teacher-Oriented Students of Mathematics in Qinghai- Tibet Plateau Area
}

\author{
Yu Wang ${ }^{1}$, Ying Wang ${ }^{1}$ and Dianjun $\mathrm{Lu}^{1, *}$ \\ ${ }^{1}$ School of Mathematics and Statistics, Qinghai Normal University, Xining, Qinghai 810008, China \\ *Corresponding author.Email:ldj@qhnu.edu.cn
}

\begin{abstract}
TPACK is the basis of effective teaching in today's era, and it is also the key content of teachers' professional development. The mastery of TPACK of the teacher-oriented students of mathematics in local colleges and universities directly affects the quality of mathematics teaching in the region in the future. The mastery of TPACK is affected by many factors such as educators' own psychological or external conditions. This study takes into account the factors affecting the mastery of TPACK, designs the teacher-oriented students of mathematics TPACK questionnaire, and conducts a full sample survey of the teacher-oriented students of mathematics in Qinghai-Tibet plateau area. The results show significant grade differences in CK, PK, PCK, TCK, TPK and TPCK of the teacher-oriented mathematics students in the Qinghai-Tibet plateau area.

Furthermore, the influence intensity of each factor on TPACK of the teacher-oriented students of mathematics in different grades is different.
\end{abstract}

Keywords: local colleges and universities; the teacher-oriented students of mathematics; TPACK; Grade

difference

\section{INTRODUCTION}

In view of the phenomenon that early teacher-oriented education research only pays attention to teacher's subject knowledge or only pays attention to teacher's teaching knowledge, Schulman [3-4] advocates the need to explore the intrinsic relationship between the two knowledge, and puts forward the subject teaching knowledge. PCK is regarded as the core part of the foundation of teaching knowledge. It also makes people deeply aware of the characteristics of teacher specialization. It is also necessary to master the corresponding information technology knowledge that can improve the teaching effect.

China is now at the end of the ten-year reform of the development of education informatization due to its vast territory, vast territory and unbalanced educational development [1-2]. This paper studies the grade difference of TPACK of the teacher-oriented students of mathematics in the Tibetan region from the perspective of influencing factors, in order to understand the grade difference of TPACK of the teacher-oriented students of mathematics in the Tibetan region and the influence mode and intensity of various influencing factors on TPACK of the teacheroriented students of mathematics in different grades, so as to put forward suggestions for the development of students' TPACK of mathematics normal education .

\section{METHODOLOGY}

\subsection{Research Tools}

The TPACK questionnaire for the teacher-oriented students of mathematics is composed of three parts. The first part is the basic information, which is used to investigate the grade of the subjects. The second part is the status of TPACK survey, a total of 25 single-choice questions, used to investigate the status of the teacher-oriented students of mathematics in the Tibetan region. A total of 164 questionnaires were distributed at the end of April 2019, and 151 valid questionnaires were collected. The reliability and validity of the collected data were tested by SPSS 20.0. The KMO value of the questionnaire is 0.900 , and the overall reliability of the questionnaire is 0.95 , which are scored by Likert's five-point method.

\subsection{Research Objects}

The reliability and validity analysis of the "TPACK Prediction Questionnaire for Mathematics Normal University Students" selected freshmen to seniors of a teacher-oriented major in mathematics in a university in Qinghai-Tibet region as the prediction sample, and 164 questionnaires were distributed at the end of April 2019. When the questionnaires were collected, invalid 
questionnaires with missing key information and the same choice of each item were eliminated. A total of 151 valid questionnaires were collected, and SPSS 20.0 was used to test the reliability and validity of the collected data. In the initial test, the KMO value of the sample appropriateness of the questionnaire was measured to be 0.900 . Further factor analysis revealed that 6 items of the 47 item variables had lost most of the information of the original variables after factor extraction. Therefore, these 6 items should be eliminated from the questionnaire. The KMO value of the questionnaire was still 0.900 after 6 items were removed, indicating that the scale was still suitable for factor analysis after 6 items were removed. The commonality of variables of the 41 items were all above 0.7 , indicating that all the 41 items in the questionnaire should be retained. Through subsequent analysis, it can be seen that all the questions are in the present dimensions, so the questionnaire has good structural validity. The final reliability statistic coefficient of "TPACK Questionnaire for Mathematics Normal University Students" composed of 41 items was 0.957 , indicating that the questionnaire had good reliability as a whole.

Table 1. Research object distribution table

\begin{tabular}{cccccc}
\hline Grade & Freshman & $\begin{array}{c}\text { Sopho- } \\
\text { more }\end{array}$ & Junior & Senior & Total \\
\hline Amount & 105 & 125 & 126 & 120 & 476 \\
\hline
\end{tabular}

\section{RESULTS AND DISCUSSION}

\subsection{Grade difference analysis of TPACK seven dimensions}

The single factor analysis of variance was used to analyzed the grade difference of TPACK seven dimensions of the teacher-oriented students of mathematics. First, the homogeneity of variance of TPACK seven dimensions of the teacher-oriented students of mathematics was tested, and the results showed that the homogeneity of variance of TK, PK, TPK and TPCK dimensions of the teacheroriented students of mathematics in different grades was less than 0.05 , indicating that the variance was not satisfied with the homogeneity, and it was necessary to use Tamhane method for subsequent analysis of variance, while the homogeneity of variance of CK, PCK and TCK dimensions was greater than 0.05 , indicating that the variance was satisfied with the homogeneity, and it was necessary to use LSD method for subsequent analysis of variance.[3]According to the data analysis ,the teacheroriented students of mathematics only TCK dimension fourth grade higher than other grades, the other six dimensions are third grade higher than other grades ; The significance value of the difference was only $0.148>0.05$ in TK dimension, indicating that there was no significant difference in TK among the four grades of the teacher- oriented students of mathematics, and the significance values of the other six dimensions were $0.000<0.05$, indicating that there were significant differences in $\mathrm{CK}$, PK, PCK, TCK, TPK and TPCK among the four grades of the teacher-oriented students of mathematics.

\subsection{Multiple comparative analysis of TPACK six dimensions}

There are significant differences in the six dimensions of the teacher-oriented students of mathematics in different grades. After multiple comparisons between grades, it is found that the teacher-oriented students of mathematics have significant differences in the $\mathrm{CK}$ dimension. There are significant differences between freshman and sophomore and other grades in PK and PCK dimensions, and there is no significant difference between junior and senior grades. There are significant differences between freshmen and other grades in TCK dimension, no significant differences between sophomores and juniors or seniors, no significant differences between juniors and seniors; There are significant differences between freshman and other grades in TPK dimension. There are significant differences between sophomore and junior, and there is no significant difference between junior and senior. There is no significant difference between junior and senior. There are significant differences between freshman and other grades in TPCK dimension. There are significant differences between sophomore and junior, and there is no significant difference between sophomore and senior. There are significant differences between junior and senior.

\subsection{Path analysis of TPACK influencing factors of the teacher-oriented students of mathematics in different grades}

From the above analysis, it can be seen that the TPACK of the teacher-oriented freshman of mathematics is higher than that of the other grades, and there are significant differences in the TPACK of the teacher-oriented senior of mathematics. In order to explore whether the reasons for the significant grade difference of TPACK are caused by the different influence ways of the five factors in the questionnaire, the structural equation model is used to study the relationship between the influencing factors and the TPACK of the teacher-oriented students of mathematics in different grades. [5-7]

\subsubsection{Path analysis of influencing factors of TPACK in the teacher-oriented freshman of mathematics}

The TPACK Forecast Questionnaire for Mathematics Normal University Students was based on the freshmen to seniors of the mathematics teacher-oriented students in a 
university in Qinghai-Tibet region. 164 questionnaires were uniformly distributed at the end of April 2019, and 151 valid questionnaires were collected. SPSS 20.0 was used to test the reliability and validity of the collected data. According to the initial test, the KMO value of the sample appropriateness of the questionnaire is 0.900 . After factor analysis, these 6 items should be eliminated. The KMO value of the follow-up test questionnaire is still 0.900 , and the commonality of variables of the 41 items is all above 0.7. The results show that the questionnaire has good structural validity. The statistical coefficient of reliability of "TPACK Questionnaire for Mathematics Normal University Students", composed of 41 questions, was 0.957 , indicating that the questionnaire had good reliability on the whole.

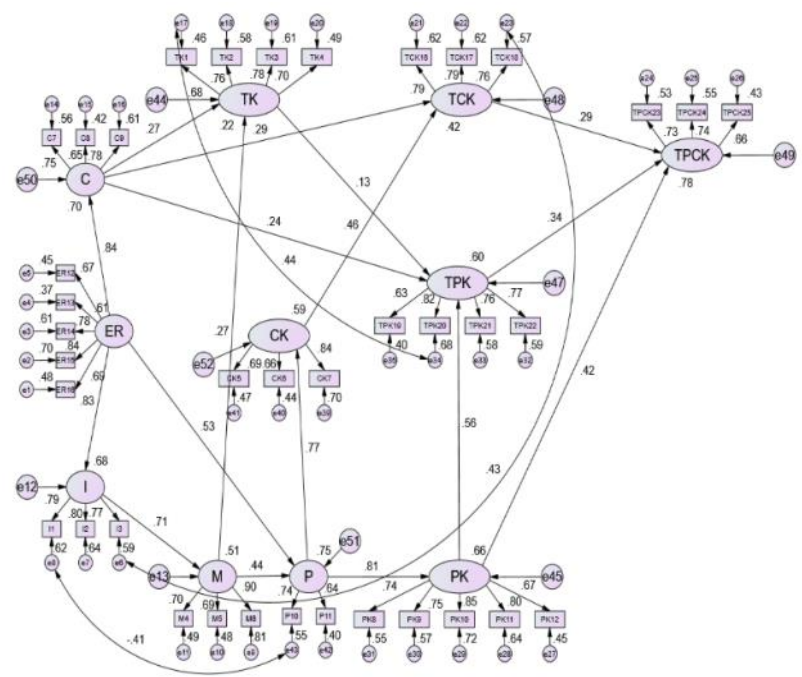

Figure 1. The TPACK influencing factor model of freshman

Table 2. Fitting index of TPACK influencing factor model of freshman

\begin{tabular}{ccrrr}
\hline Fit index & $\boldsymbol{G F I}$ & $\boldsymbol{T L I}$ & $\boldsymbol{C F I}$ & $\boldsymbol{R M S E A}$ \\
\hline $\begin{array}{c}\text { Measured } \\
\text { value }\end{array}$ & 0.922 & 0.925 & 0.948 & 0.078 \\
$\begin{array}{c}\text { Reference } \\
\text { value }\end{array}$ & $>0.9$ & $>0.9$ & $>0.9$ & $<0.08$ \\
\hline
\end{tabular}

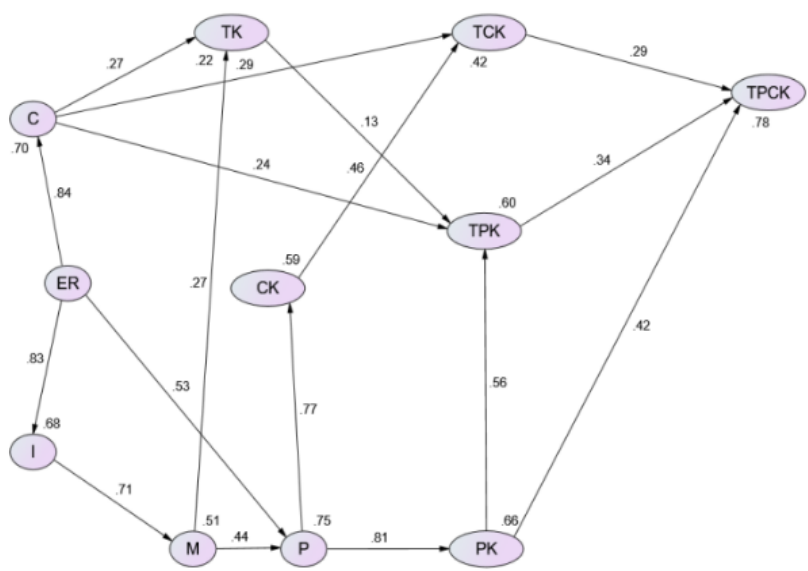

Figure 2. The path coefficient of TPACK influencing factor model of freshman

According to the data analysis, there are 17 paths in the model of the influencing factors of TPACK of the teacheroriented freshman of mathematics. This model shows how the five hypothetical influencing factors affect the TPACK of the teacher-oriented freshman of mathematics.

\subsubsection{Path analysis of TPACK influencing factors of the teacher-oriented sophomore of mathematics}

Finally, the fitting index of the TPACK influencing factor model of the teacher-oriented sophomore of mathematics is shown in table 3 , and the path coefficient diagram of the model is shown in Figure 3.

It can be seen from Table 3 that the TPACK influencing factor model of the teacher-oriented sophomore of mathematics has a good fitting degree with the data, and the estimated value of the model can be calculated. It can be seen from Figure 3 that there are 14 paths in the TPACK influencing factor model of the teacher-oriented sophomore of mathematics normal education.

Table 3. Fitting index of TPACK influencing factor model of sophomores

\begin{tabular}{lrrrr}
\hline Fit index & $\boldsymbol{G F I}$ & $\boldsymbol{T L I}$ & $\boldsymbol{C F I}$ & $\boldsymbol{R M S E A}$ \\
\hline $\begin{array}{l}\text { Measured } \\
\text { value }\end{array}$ & 0.943 & 0.952 & 0.956 & 0.066 \\
$\begin{array}{l}\text { Reference } \\
\text { value }\end{array}$ & $>0.9$ & $>0.9$ & $>0.9$ & $<0.08$ \\
\hline
\end{tabular}




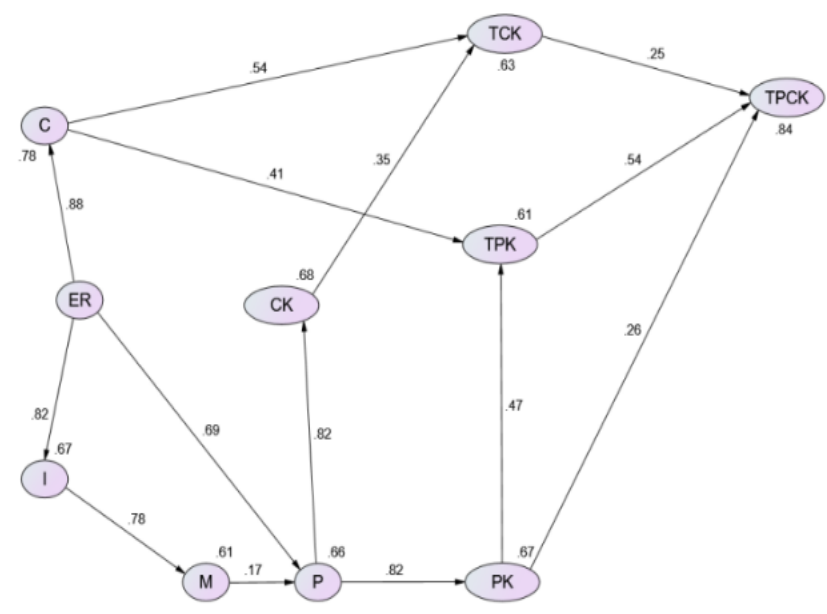

Figure 3. The path coefficient of TPACK influencing factor model of sophomores

\subsubsection{Path analysis of TPACK influencing factors of the junior of mathematics normal education}

The fitting index of the TPACK influencing factor model of the teacher-oriented junior of mathematics is shown in Table 4, and the path coefficient of the model is shown in Figure 4.

Table 4. Fitting Index of TPACK Influencing Factors Model for Grade Three Students

\begin{tabular}{crrrr}
\hline Fit index & $\boldsymbol{G F I}$ & $\boldsymbol{T L I}$ & $\boldsymbol{C F I}$ & $\boldsymbol{R M S E A}$ \\
\hline $\begin{array}{c}\text { Measured } \\
\text { value }\end{array}$ & 0.908 & 0.918 & 0.938 & 0.079 \\
$\begin{array}{c}\text { Reference } \\
\text { value }\end{array}$ & $>0.9$ & $>0.9$ & $>0.9$ & $<0.08$ \\
\hline
\end{tabular}

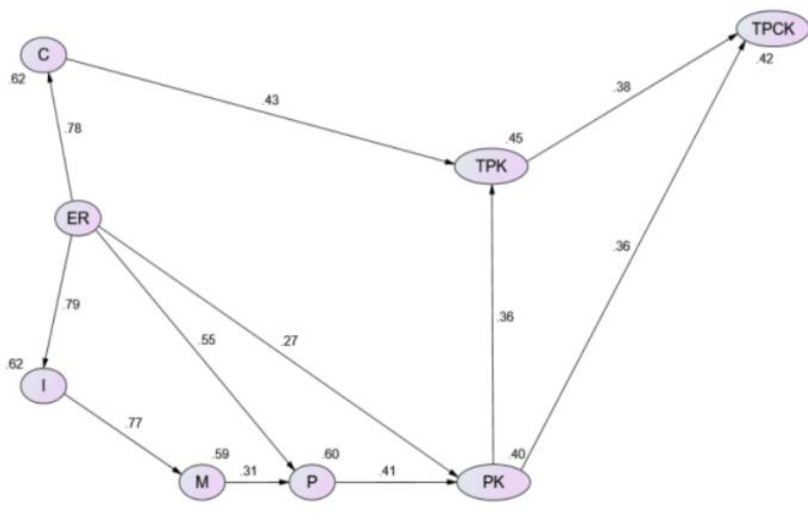

Figure 4. Path coefficient diagram of TPACK influencing factors model for junior students
From table 4, the model and data fitting degree of TPACK influencing factors of the teacher-oriented junior of mathematics are good, and the model can be used to calculate the estimated value of the model. From figure 4 , there are 15 paths in the model of TPACK influencing factors of the teacher-oriented junior of mathematics.

\subsubsection{Path analysis of TPACK influencing factors of the teacher-oriented senior of mathematics}

The fitting index of the final TPACK influencing factor model of the teacher-oriented senior of mathematics is shown in Table 5, and the path coefficient of the model is shown in Figure 5.From Table 5, the model can be used to calculate the estimated value of the model. From figure 5 , the path analysis of the model is carried out according to the analysis method of the TPACK model of the teacheroriented senior of mathematics.

Table 5. Fitting Index of TPACK Influencing Factors Model for Senior Four Students

\begin{tabular}{lrrrr}
\hline Fit index & $\boldsymbol{G F I}$ & $\boldsymbol{T L I}$ & $\boldsymbol{C F I}$ & $\boldsymbol{R M S E A}$ \\
\hline $\begin{array}{l}\text { Measured } \\
\text { value }\end{array}$ & 0.916 & 0.923 & 0.958 & 0.071 \\
$\begin{array}{l}\text { Reference } \\
\text { value }\end{array}$ & $>0.9$ & $>0.9$ & $>0.9$ & $<0.08$ \\
\hline
\end{tabular}

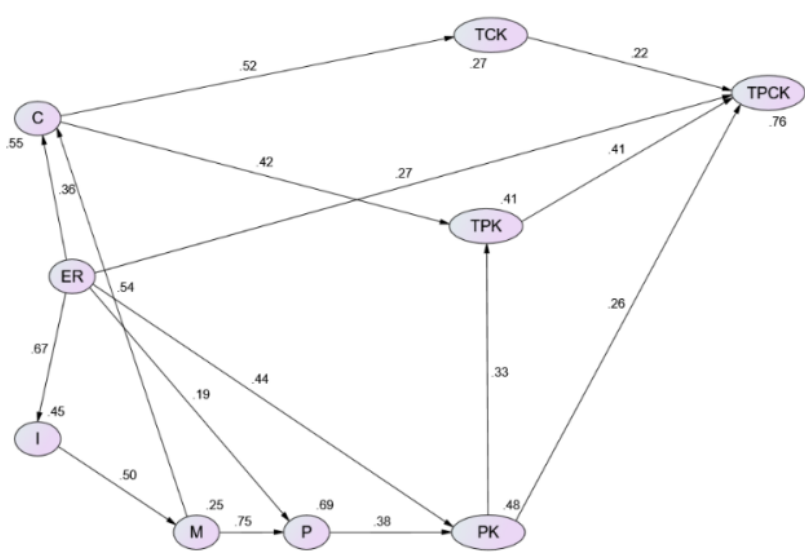

Figure 5. Path coefficient diagram of TPACK influencing factors model for senior students

\section{CONCLUSION}

(1) Only TCK dimension is higher than other grades for the teacher-oriented students of mathematics in senior year, while other six dimensions are higher than other grades in junior year. After multiple comparative analysis, the CK, PK, PCK, TPK and TPCK of the teacher-oriented students of mathematics have significantly improved after their 
sophomore and junior years of study.[8-10] At present, the primary and secondary education units in Qinghai Province still lack the resources and channels to carry out continuing education for novice teachers, and the TPACK of mathematics teachers needs to be improved.

(2) From the path coefficient diagram of each model, it can be seen that the curriculum arrangement of the freshman mathematics normal university students in Qinghai Province is relatively reasonable, while the basic knowledge is not consolidated in the course arrangement of the sophomore and junior mathematics normal university students, which leads to the weak TPACK of the senior mathematics normal university students.

(3) Teachers' professional identity, motivation and selfefficacy, teaching practice experience three factors of TPACK for freshman math teachers, education technology curriculum, school resources and environment are two factors influencing the TPACK sophomore mathematics teachers and the most. Internal psychology and teaching practice experience shows that in the early training stages of mathematics teachers has great effect, and the external conditions and education technology curriculum in the middle of the mathematics students' cultures have big role.

To sum up, colleges and universities in Qinghai-Tibet region should carry out targeted training for mathematics normal university students in each training stage to achieve the maximum development of their TPACK. For example, in the early training stage of mathematics normal university students, more ideological education activities and educational practice activities should be organized, so as to increase the professional identity and self-efficacy of mathematics normal university students and strengthen their determination to become a teacher. In the middle training stage of mathematics normal university students, educational technology related courses should be offered to students, and supporting facilities and resources should be provided, supplemented by regular educational practice, so that students can consolidate the knowledge learned in class, and timely find out the missing problems in class learning through practice, so as to check the omissions and fill the gaps.[11-13] Stage in the later stages of the mathematics teachers training should be the investment of social resources, the primary and secondary schools or relevant education departments deal with teachers to provide enough education technology training opportunities, make out of normal colleges and universities teachers can continue to learn a new education technology, schools should also encourage teachers to use modern teaching facilities, teachers can play their technical knowledge in the teaching, Put the technology to work.

\section{ACKNOWLEDGMENT}

This research was financially supported by the Applied basic research project of Qinghai province (2019-ZJ-7099).

\section{REFERENCES}

[1]T. Valtonen, U. Leppnen, M. Hyypi, E. Sointu, and J. Tondeur, "Fresh Perspectives on TPACK: Pre-Service Teachers' Own Appraisal of Their Challenging and Confident TPACK Areas," Education and Information Technologies, vol. 25(4),pp.2823-2842, 2020. DOI: $10.1007 / \mathrm{s} 10639-019-10092-4$

[2]H. Nordin, N. Davis, T. Ariffin, "A Case Study of Secondary Pre-service Teachers' Technological Pedagogical and Content Knowledge Mastery Level," Procedia - Social and Behavioral Sciences, vol. 103,pp. 1-9, 2013. DOI: 10.1016/j.sbspro.2013.10.300

[3]J.M. Clausen, E.S. Finsness, A.C. Borthwick, K.J. Graziano, J.P. Carpenter, and M. Herring, “TPACK Leadership Diagnostic Tool: Adoption and Implementation by Teacher Education Leaders," Journal of Digital Learning in Teacher Education, vol. 35(1),pp. 54-72, 2019. DOI:

https://doi.org/10.1080/21532974.2018.1537818

[4]K. Bergeson, B. Beschorner, "Modeling and Scaffolding the Technology Integration Planning Cycle for Pre-service Teachers: A Case Study," International Journal of Education in Mathematics Science and Technology, vol. 8(4),pp. 330, 2020. DOI: 10.46328/IJEMST.V8I4.1170

[5]M.L. Niess, "Preparing Teachers to Teach Science and Mathematics with Technology: Developing a Technology Pedagogical Content Knowledge," Teaching and Teacher Education, vol. 21(5),pp. 509-23, 2005. DOI: $10.1016 /$ j.tate.2005.03.006

[6]P. Lestari, N. Siregar, K. Sujaya, D.A. Mulyani, M.T. Syarifudin "Self-Determination and Technological Pedagogical Content Knowledge (TPACK): How Novice Teachers in Mathematics Education Surviving and Thriving in Disruption Era," Journal of Physics: Conference Series, vol. 1819(1):012017,pp. 7, 2021. DOI: $10.1088 / 1742-6596 / 1819 / 1 / 012017$

[7]W.N. Yanuarto, S.M. Maat, H. Husnin, "TPACK in mathematics teacher education: Are teachers ready to teach for ICT literacy?" Journal of Physics: Conference Series, vol. 1778(1):012012,pp. 11, 2021. DOI: 10.1088/1742-6596/1778/1/012012

[8]D. Akyuz, "Measuring technological pedagogical content knowledge (TPACK) through performance assessment," Computers and Education, vol. 125,pp. 212-225, 2018. DOI: 10.1016/j.compedu.2018.06.012 
[9]J.H.L. Koh, "TPACK design scaffolds for supporting teacher pedagogical change," Educational Technology Research and Development, vol. 67(3),pp. 577-595, 2019. DOI: https://doi.org/10.1007/s11423-018-9627-5

[10]M. Schmid, E. Brianza, D. Petko, "Developing a short assessment instrument for Technological Pedagogical Content Knowledge (TPACK.xs) and comparing the factor structure of an integrative and a transformative model," Computers and Education, vol. 157, 2020. DOI:

https://doi.org/10.1016/j.compedu.2020.103967

[11]M. Yigit, "A Review of the Literature: How Preservice Mathematics Teachers Develop Their Technological, Pedagogical, and Content Knowledge," International Journal of Education in Mathematics, Science and Technology, vol. 2(1), 2014. DOI: https://doi.org/10.18404/ijemst.96390
[12]J.T. Abbitt, "An Investigation of the Relationship between Self-Efficacy Beliefs about Technology Integration and Technological Pedagogical Content Knowledge (TPACK) among Preservice Teachers," Journal of Digital Learning in Teacher Education, vol. 27(4),pp. 134-143, 2011. DOI: https://doi.org/10.1080/21532974.2011.10784670

[13]S. Guerrero, "Technological pedagogical content knowledge in the mathematics classroom," Journal of Digital Learning in Teacher Education, vol. 26(4),pp. 132-139, 2010. DOI:

https://doi.org/10.1080/10402454.2010.10784646 